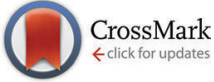

Cite this: J. Mater. Chem. C, 2016 , 4, 497

Received 6th October 2015,

Accepted 11th December 2015

DOI: $10.1039 / \mathrm{c} 5 \mathrm{tc} 03204 \mathrm{k}$

www.rsc.org/MaterialsC

\title{
Photoluminescent materials based on PMMA and a highly-emissive octahedral molybdenum metal cluster complex $\dagger$
}

\author{
Olga A. Efremova, ${ }^{* a b}$ Konstantin A. Brylev, ${ }^{\text {cde }}$ Yuri A. Vorotnikov, ${ }^{\text {cdf }}$ \\ Lucie Vejsadová, ${ }^{\text {bg }}$ Michael A. Shestopalov, ${ }^{\text {cdf }}$ Gwen F. Chimonides, ${ }^{\text {b }}$ Petr Mikes, ${ }^{9}$ \\ Paul D. Topham, ${ }^{\text {b Sung-Jin Kim, }}{ }^{\text {e Noboru Kitamura }}{ }^{\text {h }}$ and Andrew J. Sutherland ${ }^{b}$
}

\begin{abstract}
Materials that combine photoluminescence, optical transparency and facile processability are of high importance in many applications. This article reports on the development of photoluminescent poly(methyl methacrylate) materials based on novel highly emissive anionic molybdenum cluster complex $\left[\left\{\mathrm{Mo}_{6} \mathrm{I}_{8}\right\}(\mathrm{OTs})_{6}\right]^{2-}$ (where OTs ${ }^{-}$is the $p$-toluenesulfonate ion). The materials were obtained by both solution and bulk copolymerisation of methyl methacrylate and $(\mathrm{dMDAEMA})_{2}\left[\left(\mathrm{Mo}_{6} \mathrm{I}_{8}\right\}(\mathrm{OTs})_{6}\right]$, where $\mathrm{dMDAEMA}^{+}$is the polymerisable cation [2-(methacryloyloxy)ethyl]dimethyl-dodecylammonium. Evaluation of the resultant hybrid materials showed that one could combine the excellent photoluminescent properties of the cluster complex with the transparency and processability of PMMA.
\end{abstract}

\section{Introduction}

Materials fabricated from poly(methyl methacrylate) (PMMA) doped with luminescent dyes have found application in many areas of materials science, including lasing technologies, ${ }^{1}$ active optical polymer fibres for data transmission ${ }^{2}$ and luminescent solar concentrators. ${ }^{3}$ PMMA is a highly attractive material for such applications due to its outstanding optical transparency from the near-UV to the near-IR regions aligned with high thermal stability and relative inexpense of the material.

Over the last five years several works have been published that describe the doping of PMMA with photoluminescent octahedral metal cluster complexes with the general structure

\footnotetext{
${ }^{a}$ Department of Chemistry, University of Hull, Hull, HU6 7RX, UK.

E-mail: o.efremova@hull.ac.uk; Fax: +44 (0)148 246 6410;

Tel: +44 (0)148 2465417

${ }^{b}$ Chemical Engineering and Applied Chemistry, Aston University, Aston Triangle, Birmingham, B4 7ET, UK

${ }^{c}$ Nikolaev Institute of Inorganic Chemistry SB RAS, 3 Acad. Lavrentiev Ave., 630090 Novosibirsk, Russia

${ }^{d}$ Novosibirsk State University, 2 Pirogova Str., 630090 Novosibirsk, Russia

${ }^{e}$ Department of Chemistry and Nano Science, Ewha Womans University, 120-750 Seoul, Korea

${ }^{f}$ Scientific Institute of Clinical and Experimental Lymphology, 2 Timakova Str., 630060 Novosibirsk, Russia

${ }^{g}$ Department of Nonwovens and Nanofibrous Materials, Technical University of Liberec, Liberec, 46117, Czech Republic

${ }^{h}$ Department of Chemistry, Faculty of Science, Hokkaido University, 060-0810 Sapporo, Japan

$\dagger$ Electronic supplementary information (ESI) available. See DOI: 10.1039/c5tc03204k
}

$\left[\left\{\mathrm{M}_{6} \mathrm{X}_{8}\right\} \mathrm{L}_{6}\right]^{n}$, where $\mathrm{M}$ is either molybdenum or rhenium, $\mathrm{X}$ is a halogen (for Mo clusters) or chalcogen (for Re clusters) and L are apical ligands. ${ }^{4-10}$ The interest in these inorganic dyes and their hybrids with organic polymers, in particular, stems from their good luminescence in the red/NIR area combined with high emission quantum yields, long excited state lifetimes and large Stokes shifts. Specifically, luminescence in hexamolybdenum halide cluster complexes originates from a triplet excited state with both HOMO and LUMO being cluster core-centred to a large extent. ${ }^{11-13}$ Importantly, octahedral metal clusters can be easily functionalised to facilitate their incorporation into a polymer matrix. Specifically, this has been accomplished by (i) functionalisation of a metal cluster complex with a polymerisable ligand $;^{8-10}$ (ii) functionalisation of a metal cluster with a labile ligand $d^{7,8}$ or (iii) functionalisation of a cluster complex with a polymerisable cation. ${ }^{4}$ Such approaches permit the synthesis of homogeneous polymer systems without the risk of phase separation.

It was also shown recently that molybdenum complexes having a $\left\{\mathrm{Mo}_{6} \mathrm{I}_{8}\right\}^{4+}$ cluster core coordinated by residues of strong acids such as nitric acid ${ }^{8}$ and fluorinated aliphatic carboxylic acids $^{14,15}$ demonstrate outstandingly high quantum yields.

Here we report the development, and physical and luminescent properties of new PMMA-based materials that incorporate highly luminescent anionic cluster complex $\left[\left\{\mathrm{Mo}_{6} \mathrm{I}_{8}\right\}(\mathrm{OTs})_{6}\right]^{2-}$ (where $\mathrm{OTs}^{-}$ is $p$-toluenesulfonate ion) and, additionally, use of these hybrid materials to prepare microfibres by electrospinning technique.

To immobilise $\left[\left\{\mathrm{Mo}_{6} \mathrm{I}_{8}\right\}(\mathrm{OTs})_{6}\right]^{2-}$ into PMMA, we have designed a bespoke compound (dMDAEMA $)_{2}\left[\left\{\mathrm{Mo}_{6} \mathrm{I}_{8}\right\}(\mathrm{OTs})_{6}\right]$, 
which contains a polymerisable organic cation [2-(methacryloyloxy)ethyl]dimethyl-dodecylammonium $\left(\right.$ dMDAEMA $\left.^{+}\right)$. This precursor was then co-polymerised with MMA to develop PMMA/metal cluster hybrid materials.

This strategy was inspired by earlier work used for encapsulating the hexamolybdenum anionic cluster $\left[\left\{\mathrm{Mo}_{6} \mathrm{Br}_{8}\right\} \mathrm{Br}_{6}\right]^{2-}$ and polyoxometalates into PMMA. ${ }^{416}$ The major advantage of this approach to materials generation is that it produces noncrosslinked, and thus processable, polymers. The principal differences between our approach and that described previously are: (i) the halogenide salt of the polymerisable cation has been obtained in a single step from commercially available precursors and (ii) we have synthesised the intermediate compound and modified it to obtain cluster complex anion $\left[\left\{\mathrm{Mo}_{6} \mathrm{I}_{8}\right\}(\mathrm{OTs})_{6}\right]^{2-}$, which shows a significantly higher photoluminescence quantum yield than the earlier reported compounds based on the $\left[\left\{\mathrm{Mo}_{6} \mathrm{Br}_{8}\right\} \mathrm{Br}_{6}\right]^{2-}$ cluster anion. ${ }^{12}$

\section{Results and discussion}

\section{Synthesis and characterisation of polymerisable metal cluster precursor}

Our strategy to develop PMMA/metal cluster hybrid materials is based on the introduction of polymerisable organic counter cations to the di-anionic cluster $\left[\left\{\mathrm{Mo}_{6} \mathrm{I}_{8}\right\}(\mathrm{OTs})_{6}\right]^{2-}$, followed by copolymerisation with MMA. Specifically, to immobilise a highly luminescent anionic cluster complex $\left[\left\{\mathrm{Mo}_{6} \mathrm{I}_{8}\right\}(\mathrm{OTs})_{6}\right]^{2-}$ into PMMA, we have developed a bespoke precursor (dMDAE$\mathrm{MA})_{2}\left[\left\{\mathrm{Mo}_{6} \mathrm{I}_{8}\right\}(\mathrm{OTs})_{6}\right]$ (2), which includes a polymerisable organic cation dMDAEMA ${ }^{+}$. In the first stage of a simple three step synthetic process, the iodide salt of dMDAEMA $^{+}$was obtained by the reaction of 2,2-dimethylaminoethyl methacrylate and 1-iodododecane. This salt was used in a second stage for metathesis with $\mathrm{Cs}_{2}\left[\left\{\mathrm{Mo}_{6} \mathrm{I}_{8}\right\}_{6} \mathrm{I}_{6}\right]$ to produce (dMDAEMA) $2\left[\left\{\mathrm{Mo}_{6} \mathrm{I}_{8}\right\} \mathrm{I}_{6}\right]$ (1). Finally, 1 was treated with silver $p$-toluene sulfonate to produce solid (dMDAEMA) $)_{2}\left[\left\{\mathrm{Mo}_{6} \mathrm{I}_{8}\right\}(\mathrm{OTs})_{6}\right]$ (2) as an orange powder (Scheme 1).

As expected, in the ${ }^{1} \mathrm{H}$ NMR spectrum of compound 1 only signals from the cation dMDAEMA ${ }^{+}$were observed, while the spectrum of 2 features signals from both $\mathrm{OTs}^{-}$ligands and dMDAEMA $^{+}$(Fig. 1 and Fig. S1, ESI $\dagger$ ). The ratio of the

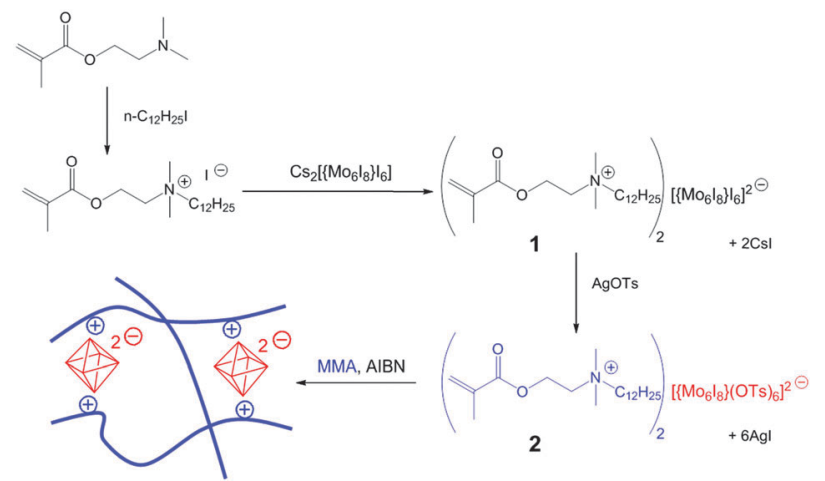

Scheme 1 Synthesis of $P M M A_{\text {bulk }}-M o^{x}$ and $P M M A_{\text {solut }}-M o^{x}$ materials.

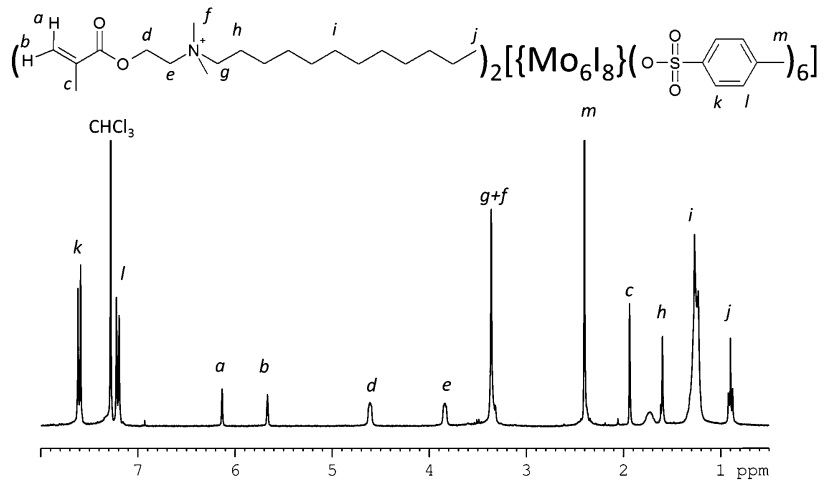

Fig. $1{ }^{1} \mathrm{H}$ NMR $(300.13 \mathrm{MHz})$ spectrum of 2 in $\mathrm{CDCl}_{3}$.

intensities of the signals confirms the assigned formula (Fig. S1, ESI $\dagger$ ). Due to the geometrical symmetry of the cluster anion only one set of signals from OTs ${ }^{-}$ligands was detected confirming the purity of the obtained complex. MS and elemental analysis further supported the proposed structure.

The presence of a long aliphatic chain (dodecyl) in the structure of 2 is crucial to increase the solubility of the cluster-containing product in low polarity liquids such as MMA. Indeed, using a similar method to that used to generate 2, we synthesised, (dMEAEMA) $2\left[\left\{\mathrm{Mo}_{6} \mathrm{I}_{8}\right\}(\mathrm{OTs})_{6}\right]$ (where dMEAEMA $^{+}$ is [2-(methacryloyloxy)ethyl]dimethyl-ethylammonium). We found that this compound is not soluble in MMA and only poorly soluble in such polar solvents as $\mathrm{CH}_{2} \mathrm{Cl}_{2}$ and acetone. Such low solubility significantly hinders copolymerisation of (dMEAEMA) $2\left[\left\{\mathrm{Mo}_{6} \mathrm{I}_{8}\right\}-\right.$ $\left.(\mathrm{OTs})_{6}\right]$ with MMA.

\section{Generation and characterisation of photoluminescent PMMA-based polymers}

Firstly, free-radical bulk polymerisation, initiated by AIBN, was employed to produce homogeneous transparent pellets, labelled as $\mathrm{PMMA}_{\text {bulk }}-\mathrm{Mo}^{x}$, where $x=0.10,0.25,1.0,2.0$ or $4.0 \mathrm{mg} \mathrm{mL}{ }^{-1}$, representing the content of 2 in a sample (Fig. S2, ESI $\dagger$ ). In this process, samples of compound 2 and the initiator were dissolved in MMA and heated at $70{ }^{\circ} \mathrm{C}$. Despite the fact that 2 contains a bulky organic cation, its solubility in MMA was still limited to $\sim 4 \mathrm{mg} \mathrm{mL}{ }^{-1}$. This solubility limit determined the highest concentration of cluster possible in the final hybrid material obtained by bulk polymerisation.

To understand further how the properties of the materials change with increased cluster content, the synthetic procedure was changed from bulk to solution-based free-radical polymerisation. In so doing, it proved possible to obtain $\mathrm{PMMA}_{\text {solut }}-\mathrm{Mo}^{x}$, where $x=5,10,50$ or $100 \mathrm{mg} \mathrm{mL}^{-1}$ relative to MMA. The choice of solvent for the polymerisation reaction (chlorobenzene) was determined by several factors: a sufficiently high boiling point to allow polymerisation, ability to readily solvate 2 and its non-coordinative nature. The latter is the key factor as $\left[\left\{\mathrm{Mo}_{6} \mathrm{I}_{8}\right\}(\mathrm{OTs})_{6}\right]^{2-}$ seems to react with the majority of coordinative solvents such as alcohols and THF, especially upon heating. This was demonstrated readily by observation of a significant change of the solution colour from orange to light-yellow, accompanied by a transformation in the 
UV spectrum of compound 2 (Fig. S3a, ESI $\dagger$ ). Moreover, the substitution of the negatively charged ligand (OTs ${ }^{-}$) by neutral THF produces species, which include the neutral complex $\left[\left\{\mathrm{Mo}_{6} \mathrm{I}_{8}\right\}(\mathrm{OTs})_{4}(\mathrm{THF})_{2}\right]$ and the positively charged complexes up to $\left[\left\{\mathrm{Mo}_{6} \mathrm{I}_{8}\right\}(\mathrm{THF})_{6}\right]^{4+}$. Such neutral and positively charged species would not interact with the positively charged polymerisable cations. In contrast, no such colour/spectral change was observed when 2 was heated in chlorobenzene, due to the non-coordinating nature of the solvent.

Although the solubility of $\mathbf{2}$ in chlorobenzene was high, the cluster-based monomer quantity was limited to $100 \mathrm{mg} \mathrm{mL}$ relative to MMA, as attempts to obtain materials with even higher contents of 2 led to precipitation of orange insoluble viscoelastic material during the polymerisation reaction.

Due to the non-covalent crosslinking nature of 2 , all other cluster-containing samples obtained were soluble in the solvents used typically to dissolve PMMA, such as toluene and THF. However, it should be noted that prolonged storage of the cluster-containing samples in THF, even at ambient temperatures, leads to slow change of the solution colour from orange to yellowish, which is presumably associated with ligand exchange.

The GPC data (Table 1 and Fig. S4, ESI $\dagger$ ) show that the molecular mass profiles of $\mathrm{PMMA}_{\text {solut }}-\mathrm{Mo}^{x}$ are similar to those of the $\mathrm{PMMA}_{\text {solut }}$ reference samples. In the case of $\mathrm{PMMA}_{\text {bulk }}{ }^{-}$ $\mathrm{Mo}^{x}$, a moderate decrease in the molecular mass was observed for samples with higher loading of the metal cluster. This may signify some sort of polymerisation inhibition/suppression, perhaps caused by local radical traps. The IR spectra obtained for the pure polymers and hybrid materials were also very similar due to the relatively low molar concentration of the cluster complex in the samples. However, in the aromatic region of the ${ }^{1} \mathrm{H}$ NMR spectra the signals of protons from benzene rings were clearly evident as was the signal of methyl group at $2.39 \mathrm{ppm}$. Moreover, these signals were stronger in samples with higher loadings of complex 2 in the polymer samples (Fig. S5, ESI $\dagger$ ). Notably, the signals in the aromatic region appeared as non-structured multiplets, which signifies some transformation of the cluster anion during the polymerisation reaction.

Differential scanning calorimetry (DSC) and thermogravimetric analysis (TGA) performed on all samples indicate that the

Table 1 Content of 2 expressed in wt\%, thermal data ( $T_{\mathrm{g}}$ and $T_{\mathrm{d}}$ ) molecular masses $\left(M_{n}\right)$ and dispersities $\left(M_{w} / M_{n}, \oplus\right)$ of copolymer samples obtained by either bulk or solution free-radical polymerisation

\begin{tabular}{lllll}
\hline & Cluster, wt\% & $T_{\mathrm{g}},{ }^{\circ} \mathrm{C}$ & $T_{\mathrm{d}},{ }^{\circ} \mathrm{C}$ & $M_{\mathrm{n}}, \mathrm{kDa}(Ð)$ \\
\hline PMMA $_{\text {bulk }}$ & - & 110 & 301 & $114(1.63)$ \\
PMMA $_{\text {bulk }}-\mathrm{Mo}^{0.10}$ & 0.011 & 106 & 305 & $128(1.89)$ \\
PMMA $_{\text {bulk }}-\mathrm{Mo}^{0.25}$ & 0.027 & 105 & 305 & $131(1.84)$ \\
PMMA $_{\text {bulk }}-\mathrm{Mo}^{1.0}$ & 0.11 & 106 & 309 & $74.3(1.70)$ \\
PMMA $_{\text {bulk }}-\mathrm{Mo}^{2.0}$ & 0.21 & 106 & 305 & $93.3(1.97)$ \\
PMMA $_{\text {bulk }}-\mathrm{Mo}^{4.0}$ & 0.42 & 103 & 305 & $63.5(1.81)$ \\
PMMA $_{\text {solut }}$ & - & 103 & 275 & $16.1(1.60)$ \\
PMMA $_{\text {solut }}-\mathrm{Mo}^{5.0}$ & 0.53 & 99 & 271 & $13.7(2.08)$ \\
PMMA $_{\text {solut }}-\mathrm{Mo}^{10}$ & 1.1 & 103 & 267 & $15.4(1.92)$ \\
PMMA $_{\text {solut }}-\mathrm{Mo}^{50}$ & 5.3 & 115 & 271 & $10.6(2.02)$ \\
PMMA $_{\text {solut }}-\mathrm{Mo}^{100}$ & 10.6 & 111 & 265 & $12.9(1.82)$
\end{tabular}

introduction of the cluster complexes resulted in almost no effect on the thermal properties of the materials. This was apparent as $T_{\mathrm{g}}$ and $T_{\mathrm{d}}$ for all cluster-containing samples were found to be close to those observed for the neat reference polymers (Table 1, Fig. S6 and S7, ESI $\dagger$ ). This indicates that the hybrid polymers can be thermally processed in a similar manner to samples of neat PMMA.

\section{Photophysical properties}

According to the absorption spectrum, a freshly prepared THF solution of compound 2 absorbs up to $\sim 500 \mathrm{~nm}$, with pronounced absorption bands at 347 and $393 \mathrm{~nm}$, which is similar to the spectrum of earlier reported complex $\left(\mathrm{Bu}_{4} \mathrm{~N}\right)_{2}\left[\left\{\mathrm{Mo}_{6} \mathrm{I}_{8}\right\}\left(\mathrm{NO}_{3}\right)_{6}\right]$ in acetone. ${ }^{8}$ Notably, the heating of the solution at $70{ }^{\circ} \mathrm{C}$ for $12 \mathrm{~h}$ leads to the disappearance of both bands and the appearance of a new band at $320 \mathrm{~nm}$, apparently associated with substitution of labile apical ligands (OTs ${ }^{-}$) by the solvent molecules. Such a hypsochromic shift of the absorption upon the ligand exchange suggests that the frontier orbitals have an appreciable input from the apical ligands as also mentioned in earlier work devoted to $\left[\left\{\mathrm{Mo}_{6} \mathrm{I}_{8}\right\} \mathrm{L}_{6}\right]^{2-}$ cluster complexes. ${ }^{17-19}$

The transmittance of the $\mathrm{PMMA}_{\text {bulk }}-\mathrm{Mo}^{x}$ samples is in accordance with the absorption spectrum of compound 2 . Indeed, with the increase of cluster complex loading, the transparency of the pelleted samples gradually decreases in the region where the blank PMMA sample is almost fully transparent, i.e. from $\sim 270$ to $\sim 500 \mathrm{~nm}$, while at longer wavelengths, the transparency is retained and is comparable with neat PMMA.

Luminescence of compound $\mathbf{2}$ was studied in the solid state and in both aerated and deaerated acetonitrile solutions. The emission spectra of compound 2 in the solid state and in deaerated acetonitrile solutions are shown in Fig. 2, while the emission maximum wavelengths $\left(\lambda_{\mathrm{em}}\right)$, quantum yields $\left(\Phi_{\mathrm{em}}\right)$, and lifetimes $\left(\tau_{\mathrm{em}}\right)$ are summarised in Table 2 . The profiles of the emission spectra of aerated and deaerated solutions for compound $\mathbf{2}$ are almost identical. However, the deaerated solution is characterised by a significantly higher quantum yield and a much longer lifetime than is observed for the aerated system (Table 2). This is due to the fact that the long-lived luminescence (i.e. phosphorescence) of hexanuclear molybdenum halide cluster complexes is well known to be quenched efficiently by dioxygen..$^{8,14,15,19-22}$ In addition, the emission spectrum of the acetonitrile solution is slightly broader relative to that of the powdered sample (Table 2), possibly due to the interaction of the emissive excited state with the solvent molecules. Emission decay profiles of aerated and deaerated acetonitrile solutions of 2 were fitted by single exponential functions, while the powdered sample of 2 exhibited double exponential decay (Table 2). The non-single exponential decay in the solid phase could be explained by an efficient excitation migration in the crystal and subsequent energy trap/ emission in the crystalline defects.

Finally, it should be noted that, as has been reported previously for other $\left\{\mathrm{Mo}_{6} \mathrm{I}_{8}\right\}^{4+}$-based complexes, ${ }^{8,15,19,22}$ the emission bands shown in Fig. 2 are relatively narrow 


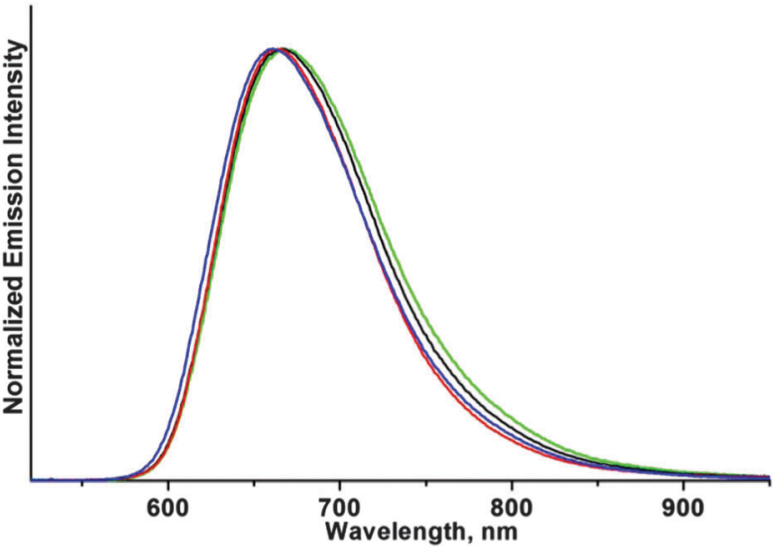

Fig. 2 Emission spectra for an acetonitrile solution (black) and the powdered sample of $\mathbf{2}$ (red); pelleted bulk polymerised (green) and powdered solution polymerised (blue) PMMA doped by the cluster complex. The excitation wavelength was $355 \mathrm{~nm}$.

Table 2 Spectroscopic and photophysical data of 2 and $\mathrm{Mo}_{6}-\mathrm{PMMA}$ hybrids

\begin{tabular}{|c|c|c|c|}
\hline Sample & $\begin{array}{l}\lambda_{\mathrm{em}}, \mathrm{nm} \\
\left(\mathrm{fwhm}, \mathrm{cm}^{-1}\right)\end{array}$ & $\begin{array}{l}\tau_{\mathrm{em}}, \mu \mathrm{s} \\
\text { (amplitude) }\end{array}$ & $\Phi_{\mathrm{em}}$ \\
\hline 2 (powdered sample) & $\sim 664(2290)$ & $\begin{array}{l}\tau_{1}=149(0.56) \\
\tau_{2}=40(0.44)\end{array}$ & 0.37 \\
\hline $\begin{array}{l}2 \text { (aerated acetonitrile } \\
\text { solution) }\end{array}$ & $\sim 667(2400)$ & 5.1 & $<0.01$ \\
\hline $\begin{array}{l}2 \text { (deaerated acetonitrile } \\
\text { solution) }\end{array}$ & $\sim 667(2400)$ & 305 & 0.65 \\
\hline $\mathrm{PMMA}_{\text {bulk }}-\mathrm{Mo}^{0.10}$ & $\sim 669(2450)$ & $\begin{array}{l}\tau_{1}=137(0.43) \\
\tau_{2}=64(0.57)\end{array}$ & 0.08 \\
\hline $\mathrm{PMMA}_{\text {bulk }}-\mathrm{Mo}^{0.25}$ & $\sim 669(2460)$ & $\begin{array}{l}\tau_{1}=140(0.39) \\
\tau_{2}=67(0.61)\end{array}$ & 0.09 \\
\hline $\mathrm{PMMA}_{\text {bulk }}-\mathrm{Mo}^{1.0}$ & $\sim 669(2490)$ & $\begin{array}{l}\tau_{1}=138(0.38) \\
\tau_{2}=66(0.62)\end{array}$ & 0.10 \\
\hline $\mathrm{PMMA}_{\text {bulk }}-\mathrm{Mo}^{2.0}$ & $\sim 669(2500)$ & $\begin{array}{l}\tau_{1}=139(0.39) \\
\tau_{2}=67(0.61)\end{array}$ & 0.18 \\
\hline $\mathrm{PMMA}_{\text {bulk }}-\mathrm{Mo}^{4.0}$ & $\sim 669(2530)$ & $\begin{array}{l}\tau_{1}=135(0.37) \\
\tau_{2}=63(0.63)\end{array}$ & 0.22 \\
\hline $\mathrm{PMMA}_{\text {solut }}-\mathrm{Mo}^{5.0}$ & $\sim 661(2400)$ & $\begin{array}{l}\tau_{1}=192(0.18) \\
\tau_{2}=104(0.82)\end{array}$ & 0.20 \\
\hline $\mathrm{PMMA}_{\text {solut }}-\mathrm{Mo}^{10}$ & $\sim 661(2410)$ & $\begin{array}{l}\tau_{1}=191(0.16) \\
\tau_{2}=107(0.84)\end{array}$ & 0.21 \\
\hline $\mathrm{PMMA}_{\text {solut }}-\mathrm{Mo}^{50}$ & $\sim 661(2420)$ & $\begin{array}{l}\tau_{1}=192(0.15) \\
\tau_{2}=106(0.85)\end{array}$ & 0.21 \\
\hline $\mathrm{PMMA}_{\text {solut }}-\mathrm{Mo}^{100}$ & $\sim 661(2420)$ & $\begin{array}{l}\tau_{1}=193(0.13) \\
\tau_{2}=108(0.87)\end{array}$ & 0.21 \\
\hline
\end{tabular}

(in comparison with emission spectra of compounds based on $\left\{\mathrm{Mo}_{6} \mathrm{Cl}_{8}\right\}^{4+}$ and $\left\{\mathrm{Mo}_{6} \mathrm{Br}_{8}\right\}^{4+}$ cores $)$.

All of the hybrid polymeric materials obtained by copolymerisation of 2 with MMA display long-lived emission, associated with the phosphorescence of the molybdenum cluster unit, with spectra extending from $\sim 580$ to $\sim 900 \mathrm{~nm}$ (Fig. 2). This is supported by the fact that the emission profiles and the $\lambda_{\mathrm{em}}$ values (Table 2 ) are similar to those found for 2 . However, the quantum yields of the polymerised samples are somewhat smaller than those recorded for both the solid sample and the deaerated acetonitrile solution of 2 .

The observed progressive growth of the determined photoluminescence quantum yields with the increase in the cluster content from $\mathrm{PMMA}_{\text {bulk }}-\mathrm{Mo}^{0.10}\left(\Phi_{\mathrm{em}}=0.08\right)$ to $\mathrm{PMMA}_{\text {bulk }}-\mathrm{Mo}^{4.0}$
$\left(\Phi_{\mathrm{em}}=0.22\right)$ can be attributed to several reasons. Firstly, it can be partially attributed to the fact that poor emission intensity of the samples with low content of the cluster makes the determination of $\Phi_{\mathrm{em}}$ by Absolute Photo-Luminescence Quantum Yield Measurement System unreliable because signal-to-noise levels of the experiments are too low.

Secondly, bulk PMMA itself has a non-zero absorption at $400 \mathrm{~nm}$ and above (Fig. S3b, ESI $\dagger$ ), which results in an inner filter effect. Therefore, the quantum yield, defined as the ratio of the number of emitted photons from the cluster complex to the number of absorbed photons, becomes lower and the inner filter effect becomes more pronounced for the samples with low metal cluster content.

Thirdly, the increase in $\Phi_{\mathrm{em}}$ values with increase in cluster content could be also explained by the supposition that the microenvironment around the cluster complex depends on its content in PMMA and this leads to variations in the emission quantum yield. Indeed, according to Table 1 , the $M_{\mathrm{n}}$ value decreases with increase in cluster content, indicating the microenvironment around the cluster complex in a low content is very much crowded. Consequently, intermolecular interactions between the excited state cluster and polymer side chains bring about a fast deactivation to the ground state, causing a relatively low quantum yield. In contrast, the high cluster content samples possess low $M_{\mathrm{n}}$ suggesting that the cluster-polymer interaction will be less effective, resulting in a higher emission quantum yield.

The emission of cluster-doped bulk polymers exhibited double exponential decays. The decay parameters [lifetimes and their amplitudes $(A)$ ] were very similar for all of the bulk samples despite their differing cluster contents (Table 2): the short and long lifetime components were $\sim 63-67 \mu \mathrm{s}(A=\sim 0.57-$ $0.63)$ and $\sim 135-140 \mu \mathrm{s}(A=\sim 0.37-0.43)$, respectively.

The cluster solubility in MMA (4 $\left.\mathrm{mg} \mathrm{mL}^{-1}\right)$ significantly limited the cluster complex loading that could be incorporated into the PMMA matrix. Accordingly, solution polymerisation was exploited as an alternative approach to prepare hybrid materials with far higher cluster luminophore content. Gratifyingly, it proved possible to considerably increase the concentration up to a level of $100 \mathrm{mg} \mathrm{mL}{ }^{-1}$. However, despite being able to increase cluster content so markedly, there was little change in emission quantum yields of the resulting hybrid polymer materials in going from 5 to $100 \mathrm{mg}$ of 2 to $1 \mathrm{~mL}$ of MMA (Table 2). Indeed, $\Phi_{\mathrm{em}}$ was found to be almost the same as the quantum yield recorded for a pellet of bulk polymerised PMMA with the highest concentration of the cluster complex.

As with the cluster-doped bulk polymers, the emission of the solution-polymerised samples also exhibited double exponential decays. Again, the lifetimes and their amplitudes were similar for samples with different cluster contents: the short and long lifetime components were $\sim 104-108 \mu \mathrm{s}(A=\sim 0.82-0.87)$ and $\sim 192-193 \mu$ s $(A=\sim 0.13-0.18)$, respectively. However, both the short and long lifetimes were considerably higher than those of the bulk polymerised samples.

Interestingly, the emission maximum wavelengths of the pelleted PMMA samples $\left(\mathrm{PMMA}_{\mathrm{bulk}}-\mathrm{Mo}^{x}\right)$ were slightly 
red-shifted relatively to that of the acetonitrile solution of 2 , while the $\lambda_{\text {em }}$ of the powdered materials $\left(\mathrm{PMMA}_{\text {solut }}-\mathrm{Mo}^{x}\right)$ were somewhat blue-shifted (Fig. 2 and Table 2). At the same time the emission profiles of the powders have similar broadness (fwhm, $\sim 2400 \mathrm{~cm}^{-1}$ ) to that of the acetonitrile solution of 2 , whereas they are distinctly narrower than the emission profiles of the pelleted materials.

Our observations regarding changes in emission profiles/ properties, outlined above, align well with work reported recently by the Molard group. ${ }^{23}$ In their study, focusing on polyurethane-based systems, very similar observations were reported for polymer materials in comparison with a starting polymerisable complex in a $\left[\left\{\mathrm{Mo}_{6} \mathrm{I}_{8}\right\}\left(\mathrm{OCOC}_{2} \mathrm{~F}_{5}\right)_{6}\right] @ P U$ system (where PU is polyurethane). ${ }^{23}$ Namely, the characterisation of photophysical properties of the hybrid materials revealed slight changes in the emission profile of the polymer samples (the emission maxima and the fwhm) in comparison with the starting complex and significant changes in the photoluminescence quantum yields for all samples with only one sample having $50 \%$ concentration of the cluster complex achieving quantum yield 0.7 , which is close to the quantum yield of the starting compound (0.8). A possible explanation for the change in photophysical characteristics, including the reduced quantum yield of the polymeric samples in both pieces of work is some sort of a degradation of the original highly emissive anionic cluster complexes $\left[\left\{\mathrm{Mo}_{6} \mathrm{I}_{8}\right\}(\mathrm{OTs})_{6}\right]^{2-}$ and $\left[\left\{\mathrm{Mo}_{6} \mathrm{I}_{8}\right\}\left(\mathrm{OCOC}_{2} \mathrm{~F}_{5}\right)_{6}\right]^{2-}$ under the conditions of the polymerisation reactions. This could be due to the chemical instability of the complexes under raised temperature, which, for example, could cause full or partial substitution of the labile ligands $\mathrm{OTs}^{-}$or $\mathrm{C}_{2} \mathrm{~F}_{5} \mathrm{COO}^{-}$, respectively, by species present in the reaction mixtures (e.g. monomers, initiator by-products, etc.). The slight differences in the values of photoluminescence lifetimes and the emission profiles between bulk and solution polymerised sets of samples may signify that the level of the cluster complex transformation, or even the mechanism of the transformation, is different in the presence of solvent. However, there may be other factors at play and the real reason/mechanism for the observed changes remains to be discovered. Indeed in the aromatic region of the spectra of the polymers it is possible to see some change in the shape of the signal from the tosylate ligand, which may signify the distortion of the symmetric shape of the cluster anion associated with partial substitution of the tosylate ligands.

\section{Fibres and their properties}

Electrospinning is a widely used polymer processing technique for generating functional fibrous materials. ${ }^{24-27}$ The method is relatively inexpensive to employ and is capable of producing fibres with diameters ranging from a few micrometres down to a few hundred nanometres. Polymer fibres produced from PMMA doped with photoluminescent entities are of particular interest. ${ }^{28}$ Applications of such fibres include use in lasers, ${ }^{29-31}$ optical waveguides, ${ }^{32,33}$ gas sensors, ${ }^{34}$ solid-state lighting technologies, ${ }^{35,36}$ etc. Moreover, the earlier work of Kirakci et al. ${ }^{14}$ showed that that fibres obtained by electrospinning a solution of polyurethane and $\left(\mathrm{Bu}_{4} \mathrm{~N}\right)_{2}\left[\left\{\mathrm{Mo}_{6} \mathrm{I}_{8}\right\}\left(\mathrm{OOCCF}_{3}\right)_{6}\right]$ acquired the ability of the metal cluster complex to generate singlet oxygen. Accordingly, it is of general interest and utility to identify and establish processing parameters to electrospin our cluster-containing hybrid polymers.

After some initial screening experiments, it was found that $25 \%$ chloroform solutions of $\mathrm{PMMA}_{\text {solut }}-\mathrm{Mo}^{x}(x=5.0,10,50$ or 100) could be used to obtain fibres by electrospinning. Here, polymers generated by solution polymerisation were selected for two major reasons. Firstly, the samples obtained by solution polymerisation have similar photophysical properties regardless of the cluster complex content. Secondly, these polymers were also shown to have better solubility than the bulk-prepared samples.

Fig. 3 shows a typical SEM micrograph of a mat of microfibres produced from $\mathrm{PMMA}_{\text {solut }}-\mathrm{Mo}^{x}$. In this example, the fibres were generated from $\mathrm{PMMA}_{\text {solut }}-\mathrm{Mo}^{100}$. These exemplar

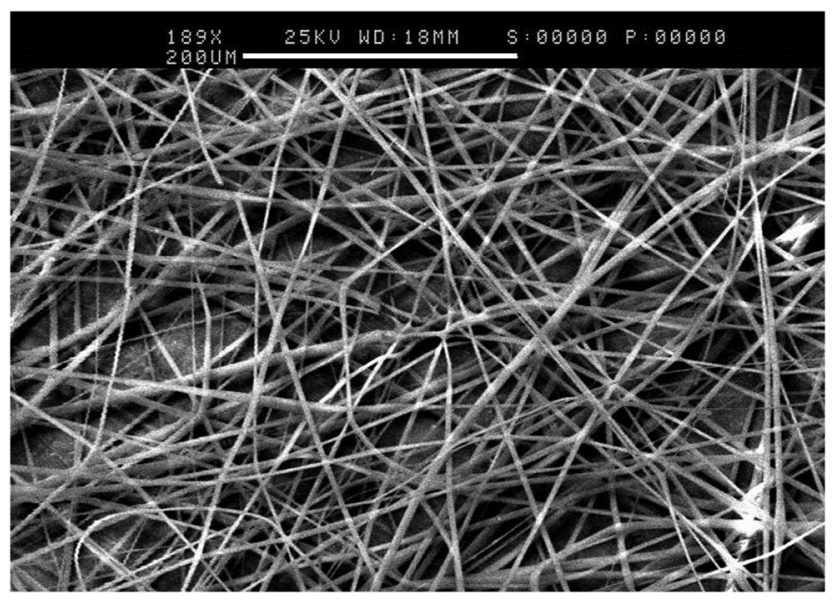

Fig. 3 SEM image of the electrospun fibres of $P M M A_{\text {solut }}-M 0^{100}$
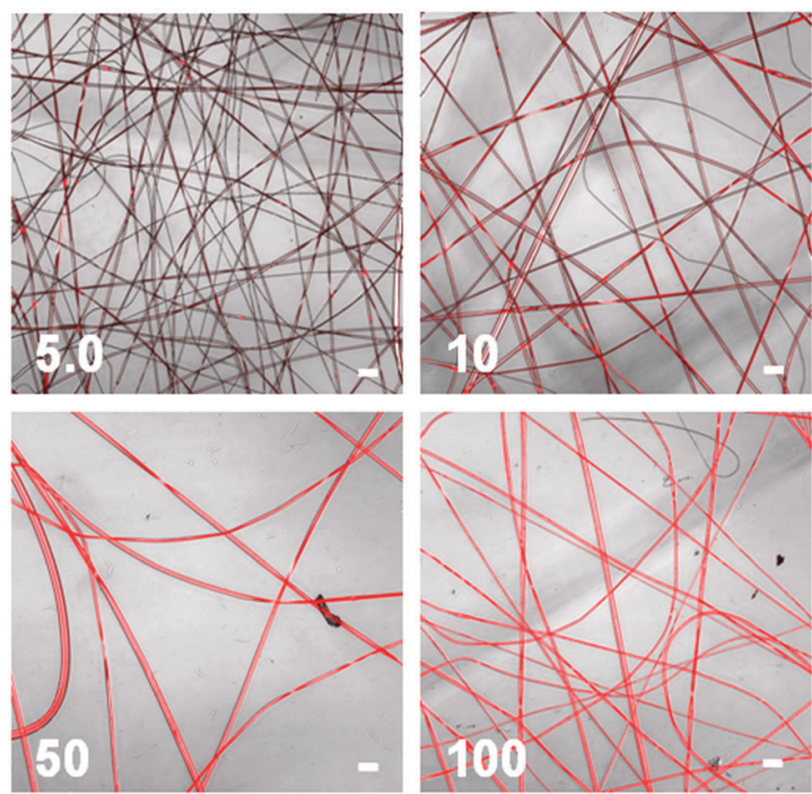

Fig. 4 Confocal images of fibres obtained from $\mathrm{PMMA}_{\text {solut }}-\mathrm{Mo}^{\mathrm{x}}$, where $x=5.0,10,50$ or 100 . The white scale bars represent $30 \mu \mathrm{m}$. 
fibres have diameter sizes in the range of 1-10 $\mu \mathrm{m}$, with the average diameter of the fibres being in the range of 3-4 $\mu \mathrm{m}$ (see Table S1, ESI $\dagger$ for fibre dimension data for all of the $\mathrm{PMMA}_{\text {solut }}-\mathrm{Mo}^{x}$ hybrids).

Fluorescent confocal microscopy was used to assess the effect of cluster content on fibre emission and the resultant images (Fig. 4) clearly show increasing brightness of emission with increasing cluster content in the material. In addition, the images of $\mathrm{PMMA}_{\text {solut }}-\mathrm{Mo}^{5}$ and $\mathrm{PMMA}_{\text {solut }}-\mathrm{Mo}^{10}$ fibre samples appear to give emissions that are less homogeneous along the fibres than those from samples with higher cluster contents. Higher resolution confocal microscopy images of a single $\mathrm{PMMA}_{\text {solut }}-\mathrm{Mo}^{5}$ fibre (Fig. S8, ESI $\dagger$ ) and a further SEM image (Fig. S9, ESI $\dagger$ ) of a collection of these low cluster content fibres show defects in the fibres such as pores and bubbles. These defects coincide with the brighter spots in confocal images (Fig. S8, ESI $\dagger$ ).

\section{Conclusions}

A compound based on a highly emissive anionic hexamolybdenum cluster complex and a polymerisable cation has been successfully synthesised. This compound was subsequently employed as a monomer to obtain photoluminescent materials by copolymerisation with MMA using both bulk and solution-based free-radical polymerisation techniques. The hybrid polymer materials could be successfully obtained with variable loadings of the cluster complex up to $100 \mathrm{mg}$ per $1 \mathrm{~mL}$ of monomer without significant changes to the physical properties of the polymer. Comparison of the photophysical properties of the obtained polymeric materials with those of starting polymerisable compound revealed that both polymerisation reaction techniques (in bulk and in solution) had an effect on the photoemission properties of the resultant materials. This suggests that the polymerisation reaction conditions cause some minor degradation of the metal cluster, presumably associated with OTs $^{-}$ligand substitution. Despite this, the photoluminescence quantum yields determined for the materials still had reasonably high values of $20-22 \%$.

Study of the thermal properties suggested that the developed PMMA-based materials can be used for thermal processing as they show similar thermal behaviour as neat PMMA. Furthermore, the materials were shown to be amenable for solution-based processing as they were successfully used in electrospinning experiments to generate photoluminescent fibres.

\section{Acknowledgements}

This work was supported by a Marie Curie Inter-European Fellowship (Grant no. 327440), the Russian Science Foundation (Grant no. 14-14-00192) and the Royal Society (Grant no. IE140281). Also K. A. Brylev thanks the Brain Pool Program of the Korean Federation of Science and Technology Societies (KOFST) funded by the Ministry of Science, ICT and Future Planning (151-S-1-3-1190).

\section{Notes and references}

1 S. Chénais and S. Forget, Polym. Int., 2012, 61, 390-406.

2 K. Peters, Smart Mater. Struct., 2011, 20, 013002.

3 B. C. Rowan, L. R. Wilson and B. S. Richards, IEEE J. Sel. Top. Quantum Electron., 2008, 14, 1312-1322.

4 M. Amela-Cortes, A. Garreau, S. Cordier, E. Faulques, J. L. Duvail and Y. Molard, J. Mater. Chem. C, 2014, 2, 1545-1552.

5 S. Cordier, Y. Molard, K. A. Brylev, Y. V. Mironov, F. Grasset, B. Fabre and N. G. Naumov, J. Cluster Sci., 2015, 26, 53-81.

6 A. Garreau, F. Massuyeau, S. Cordier, Y. Molard, E. Gautron, P. Bertoncini, E. Faulques, J. Wery, B. Humbert, A. Bulou and J. L. Duvail, ACS Nano, 2013, 7, 2977-2987.

7 Y. Molard, C. Labbe, J. Cardin and S. Cordier, Adv. Funct. Mater., 2013, 23, 4821-4825.

8 O. A. Efremova, M. A. Shestopalov, N. A. Chirtsova, A. I. Smolentsev, Y. V. Mironov, N. Kitamura, K. A. Brylev and A. J. Sutherland, Dalton Trans., 2014, 43, 6021-6025.

9 Y. Molard, F. Dorson, K. A. Brylev, M. A. Shestopalov, Y. Le Gal, S. Cordier, Y. V. Mironov, N. Kitamura and C. Perrin, Chem. - Eur. J., 2010, 16, 5613-5619.

10 O. A. Efremova, K. A. Brylev, O. Kozlova, M. S. White, M. A. Shestopalov, N. Kitamura, Y. V. Mironov, S. Bauer and A. J. Sutherland, J. Mater. Chem. C, 2014, 2, 8630-8638.

11 A. W. Maverick and H. B. Gray, J. Am. Chem. Soc., 1981, 103, 1298-1300.

12 A. W. Maverick, J. S. Najdzionek, D. MacKenzie, D. G. Nocera and H. B. Gray, J. Am. Chem. Soc., 1983, 105, 1878-1882.

13 M. Ströbele, T. Jüstel, H. Bettentrup and H.-J. Meyer, Z. Anorg. Allg. Chem., 2009, 635, 822-827.

14 K. Kirakci, P. Kubat, M. Dusek, K. Fejfarova, V. Sicha, J. Mosinger and K. Lang, Eur. J. Inorg. Chem., 2012, 3107-3111.

15 M. N. Sokolov, M. A. Mihailov, E. V. Peresypkina, K. A. Brylev, N. Kitamura and V. P. Fedin, Dalton Trans., 2011, 40, 6375-6377.

16 H. Li, W. Qi, W. Li, H. Sun, W. Bu and L. Wu, Adv. Mater., 2005, 17, 2688-2692.

17 L. M. Robinson, R. L. Bain, D. F. Shriver and D. E. Ellis, Inorg. Chem., 1995, 34, 5588-5596.

18 K. Kirakci, P. Kubát, M. Kučeráková, V. Šícha, H. Gbelcová, P. Lovecká, P. Grznárová, T. Ruml and K. Lang, Inorg. Chim. Acta, 2016, 441, 42-49.

19 K. Kirakci, P. Kubat, J. Langmaier, T. Polivka, M. Fuciman, K. Fejfarova and K. Lang, Dalton Trans., 2013, 42, 7224-7232.

20 K. Kirakci, K. Fejfarová, M. Kučeráková and K. Lang, Eur. J. Inorg. Chem., 2014, 2331-2336.

21 K. Kirakci, V. Šícha, J. Holub, P. Kubát and K. Lang, Inorg. Chem., 2014, 53, 13012-13018.

22 M. N. Sokolov, M. A. Mikhailov, K. A. Brylev, A. V. Virovets, C. Vicent, N. B. Kompankov, N. Kitamura and V. P. Fedin, Inorg. Chem., 2013, 52, 12477-12481.

23 M. Amela-Cortes, S. Paofai, S. Cordier, H. Folliot and Y. Molard, Chem. Commun., 2015, 51, 8177-8180.

24 J. Doshi and D. H. Reneker, J. Electrost., 1995, 35, 151-160. 25 Z. M. Huang, Y. Z. Zhang, M. Kotaki and S. Ramakrishna, Compos. Sci. Technol., 2003, 63, 2223-2253.

26 D. H. Reneker and I. Chun, Nanotechnology, 1996, 7, 216-223. 
27 L. G. Wang, M. Wang, P. D. Topham and Y. Huang, RSC Adv., 2012, 2, 2433-2438.

28 P. Wang, Y. P. Wang and L. M. Tong, Light: Sci. Appl., 2013, 2, e102.

29 A. Camposeo, F. Di Benedetto, R. Stabile, A. A. R. Neves, R. Cingolani and D. Pisignano, Small, 2009, 5, 562-566.

30 A. Camposeo, L. Persano and D. Pisignano, in Proc. SPIE 8829, Organic Light Emitting Materials and Devices XVII, ed. F. So and C. Adachi, San Diego, California, United States, September 27, 2013, p. 882918.

31 L. Persano, A. Camposeo, C. Tekmen and D. Pisignano, Macromol. Mater. Eng., 2013, 298, 504-520.
32 Y. Ishii, R. Kaminose and M. Fukuda, J. Phys.: Conf. Ser., 2013, 433, 012006.

33 H. Q. Liu, J. B. Edel, L. M. Bellan and H. G. Craighead, Small, 2006, 2, 495-499.

34 F. Gu, L. Zhang, X. Yin and L. Tong, Nano Lett., 2008, 8, 2757-2761.

35 L. Davis, L. Hana, P. Hoertza, K. Guzana, K. C. Millsa, H. J. Walls, T. A. Walker and D. Magnus-Aryitey, MRS Proc., 2009, 1240, WW09-07.

36 S. Y. Min, J. Bang, J. Park, C. L. Lee, S. Lee, J. J. Park, U. Jeong, S. Kim and T. W. Lee, RSC Adv., 2014, 4, 11585-11589. 